\title{
Gap Junction Formation in Rabbit Uterine Epithelium in Response to Embryo Recognition
}

\author{
Elke Winterhager, ${ }^{1}$ F. BrUmmer, ${ }^{2}$ R. Dermietzel, ${ }^{3}$ D. F. HUlser, ${ }^{2}$ and H.-W. Denker \\ Abteilung Anatomie der RWTH Aachen, Melatener Strasse 211, D-5100 Aachen, West Germany
}

Accepted November 24, 1987

\begin{abstract}
Gap junction formation was studied in the uterine epithelium of nonpregnant, pregnant, and pseudopregnant rabbits in the periimplantation phase $(6,7,8$ days post coitum/post human gonadotropin injection) using freeze-fracture and immunocytochemistry as well as intracellular Lucifer yellow injection. At implantation ( 7 days post coitum) the uterine epithelial cells of the implantation chamber become junctionally coupled as evidenced by all three methods used. Gap junction protein $(26 \mathrm{~K})$ becomes detectable immunocytochemically with a monoclonal antibody at 6 days post coitum in the epithelium surrounding the blastocyst, i.e., in the forming implantation chamber. The same sequence of events, starting with the presence of the gap junction protein before cell-to-cell coupling becomes evident, was observed in the blastocyst-free segments 1 day later. In contrast, uterine epithelium of nonpregnant and pseudopregnant animals in comparable phases shows an extremely low degree of coupling. The presence of the blastocyst is a necessary condition for the induction of gap junctions as demonstrated by unilateral pregnancy produced by tubal ligation. Thus, gap junction formation is one of the first maternal responses to a locally acting signal of the blastocyst. (- 1988 Academic Press, Inc.
\end{abstract}

\section{INTRODUCTION}

Implantation of the mammalian blastocyst in the uterus involves a complex set of cell biological changes in the endometrium which are incompletely understood (for review see Finn, 1977). One aspect of this so-called "implantation reaction" has been relatively well investigated, i.e., the preconditioning by systemic hormone action (Psychoyos, 1976; Finn, 1977). In addition to this, however, a local signaling must also exist which causes the part of the endometrium adjacent to the blastocyst (endometrium of the "implantation chamber") to allow attachment and invasion of the trophoblast (for review see Kennedy, 1983). The uterine epithelium is of particular importance in this respect for the following reasons: (1) It acts as a signal transducer for the messages from the blastocyst to the endometrial stroma, (2) it is the first partner for trophoblast attachment, and (3) it must undergo dramatic changes resulting in loss of part of its typical epithelial propertics (Denker, 1986). Little is known about the changes in the cell physiological state of the uterine epithelium that are locally induced by the blastocyst.

We are reporting here on an induction of cell-to-cell communication in the uterine epithelium which starts locally in the implantation chamber and which may

\footnotetext{
1 To whom reprint requests should be addressed.

${ }^{2}$ Biologisehes Institut, Universität Stuttgart, Pfaffenwaldring 57 , 7000 Stuttgart, West Germany.

${ }^{3}$ Institut für Anatomie, Universität Essen (GH), Hufelandstrasse 55, 4300 Essen 1, West Germany.
}

form an essential and previously unknown part of the implantation reaction.

\section{MATERIALS AND METHODS}

Sexually mature, mixed breed female rabbits (3-4 kg in weight) were either mated each to two fertile males (pregnancy) or injected intravenously with $75 \mathrm{IU}$ human chorionic gonadotropin (hCG) in order to induce ovulation (pseudopregnancy). The animals were sacrificed 6,7 , and 8 days post coitum (d p.c.)/post hCG (d p. hCG) together with nonpregnant controls.

\section{Electron Microscopy}

A total number of 34 animals was used for freezefracture investigations. Anesthetized animals (Sodium pentobarbital, Nembutal, $24 \mathrm{mg} / \mathrm{kg}$ ) were perfused via the thoracic aorta with a mixture of $2 \%$ paraformaldehyde and $2.5 \%$ glutaraldehyde in $0.1 \mathrm{M}$ cacodylate buffer ( $\mathrm{pH}$ 7.4). Samples were taken from different parts of the uteri: next to the cervix, middle part of the uterus, and next to the tube. A minimum of three implantation chambers per pregnant animal was investigated. The mesometrial and the antimesometrial region were studied separately. For explanation of the anatomy of the pregnant uterus of the rabbit see Fig. 1. From these regions a minimum of 18 replicas per implantation chamber and blastocyst-free segment was prepared. The processing for freeze-fracturing and replication have been described previously (Winterhager $e t$ al., 1984). Replicas were viewed in a Zeiss EM 10. 


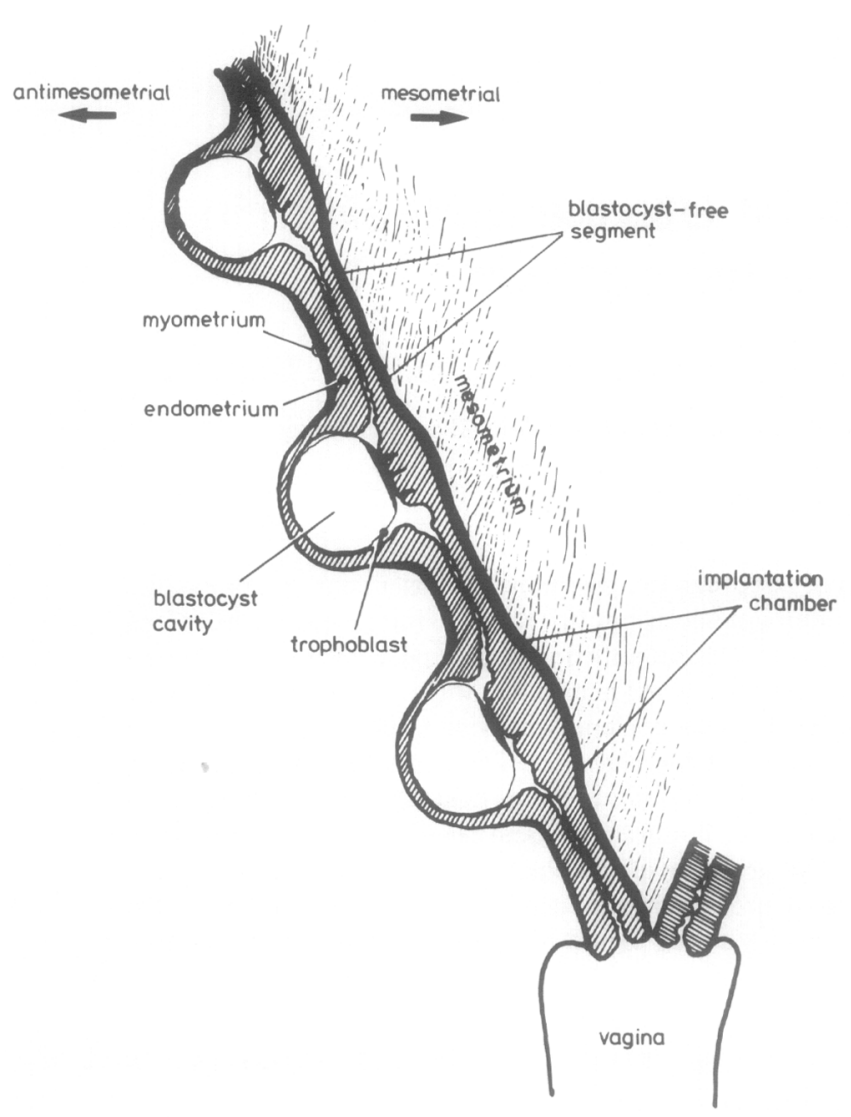

FIG. 1. Schematic drawing of the uterus duplex of the rabbit at about $8 \mathrm{~d}$ p.c., demonstrating anatomical details. The mucosa was studied separately in different parts: blastocyst-free segments and implantation chamber, in each case discriminating between the mesometrial and antimesometrial sides.

\section{Immunocytochemistry}

For immunocytochemistry a monoclonal antibody (12-1 C5) kindly provided by Professor K. Willecke (Essen, FRG) was used. Briefly, rats were immunized with purified mouse liver gap junction plaques as well as $26 \mathrm{~K}$ protein (SDS denaturated). The rat monoclonal antibody was isolated from hybridoma culture supernatant by affinity chromatography. It recognized mouse liver $26 \mathrm{~K}$ protein after SDS electrophoresis and immunoblotting of purified gap junctions or mouse liver membranes (Janssen-Timmen et al., 1986). Uteri and implantation chambers of a minimum of two animals per reproductive phase were investigated. Pieces of the uteri were freshly frozen in liquid nitrogen and sectioned 8-10 $\mu \mathrm{m}$ thick on a cryostat. Sections were mounted on glass coverslips and fixed in absolute ethanol for $30 \mathrm{~min}$ at $-25^{\circ} \mathrm{C}$. After a rinse in $0.1 \mathrm{M}$ phosphate-buffered saline (PBS), the sections were layered with $0.1 \%$ bovine serum albumin in PBS for $15 \mathrm{~min}$ to reduce nonspecific labeling and then for $1 \mathrm{hr}$ at room temperature with $30 \mu$ of the monoclonal antibody in a concentration of $0.1 \mu \mathrm{g} / \mathrm{ml}$, followed by PBS rinse. FITC-labeled sheep anti-rat IgG (Miles, Munich) diluted 1:1000 was used as a second antibody. After incubation with the second antibody for $45 \mathrm{~min}$ at room temperature sections were rinsed in PBS, mounted on slides with glycerol/phenylenediamine, and studied with a Zeiss photomicroscope equipped with epifluorescence illumination and appropriate filters for FITC fluorescence. Controls were performed with rat nonimmune serum, rat IgG, and unconditioned tissue culture medium.

\section{Microiontophoresis}

The gap junction formation in the uterine epithelium was demonstrated by iontophoretic microinjection of Lucifer yellow CH (mol wt 457.3; Sigma) (Stewart, 1978; Iwatsuki and Petersen, 1979). For this purpose small pieces of fresh uteri were mounted in a petri dish filled with PBS ( $\mathrm{pH} 7.4)$ at $37^{\circ} \mathrm{C}$. Capillaries of borosilicate glass (1 $\mathrm{mm}$ in outer diameter; Hilgenberg) with inner filaments were pulled into micropipets by a vertical pipet puller (David Kopf Instruments, tip diameter about $0.1 \mu \mathrm{m}$ ) and filled with a $4 \%$ solution of Lucifer yellow in distilled water. The dye was injected for about 2-4 sec using 10-nA negative current pulses (WPI, Microiontophoresis Programmer 160). The microelectrodes were operated by a micromanipulator (Märzhäuser) under a microscope (Zeiss Photomikroskop) equipped with phase-contrast and epifluorescence illumination. For these investigations a total number of 14 animals was tested. The incidence of transferring junctions was scored in first-order neighbors $\left(n_{1}\right.$-coupled), i.e., the dye spreads into direct neighboring cells, and in higher ordered neighbors ( $>n_{1}$-coupled). This score is used according to Flagg-Newton and Loewenstein (1981).

\section{Tubal Ligation Experiments}

In order to allow the comparison of a blastocystbearing with a blastocyst-free uterus within the same animal, unilateral tubal ligation was performed in two animals. Female rabbits were laparotomized under thiobarbiturate anesthesia (Thiogenal) after neuroleptic premedication (Perphenazin, Decentan) (Gottschewski and Zimmermann, 1970) at 1 d p.c., i.e., when embryos have not yet reached the uterus. At 7 d p.c. perfusion fixation and preparation for freeze-fracture investigations were performed as described above.

\section{Quantification of Gap Junctions}

Fifty photographs were taken from freeze-fracture replicas of uterine epithelial cells in the implantation 
chamber at 7 and $7 \frac{1}{2}$ d p.c., original magnification $25,000 \times$, printed at $57,000 \times$. For morphometric evaluation, a total area of $265 \mu \mathrm{m}^{2}$ of uterine epithelial membrane was investigated using a MOP system (Kontron). The mean $\pm \mathrm{SE}$ of gap junction area was calculated and expressed as a percentage of the total membrane area.

\section{RESULTS}

\section{Nonpregnant State}

Freeze-fracture replicas of the uterine epithelium in the nonpregnant state reveal that lateral membranes exhibit very few gap junctions. The few that could be found (1 gap junction per approx $1000 \mu \mathrm{m}^{2}$ membrane area observed) consisted of small aggregates of loosely arranged particles (Fig. 3). This is in accordance with observations published previously (Winterhager and Kühnel, 1982).

In addition, immunocytochemistry showed no reaction against the gap junction subunit (26K protein) in the epithelium of nonpregnant animals. Microinjection of Lucifer yellow performed in freshly isolated endometrium of nonpregnant animals (Figs. 11a and 11b) demonstrated that the dye remained within the injected epithelial cell. These experiments (Table 1 and 2) lend evidence for a noncoupled state of the uterine epithelium in the nonpregnant stage.

\section{Pregnancy}

$6 d$ p.c. During the preimplantation phase of pregnancy the blastocyst becomes immobilized in the uterus at $6 \mathrm{~d}$ p.c., so that an implantation chamber is formed (Fig. 1). A cellular contact between trophoblast and uterine epithelium, however, is established only 1 day later. During the preimplantation phase, the epithelial cells of the forming implantation chamber as well as those in blastocyst-free segments undergo a morphological transformation including changes in the tight junctions which proliferate toward the basal portion of the lateral membrane (Fig. 2). There is no indication, from freeze-fractures, of the formation of additional gap junctions in any part of the epithelium as compared with the nonpregnant state.

As scen in Table 1, intracellular Lucifer yellow injection demonstrated that most of the cells were uncoupled at this early phase, except for some which exhibited a low degree of coupling indicated by a transfer of the dye into one or two directly neighboring cells ( $n_{1}$-coupled).

Immunocytochemistry performed in the same phase, however, revealed a clear reaction indicating that the $26 \mathrm{~K}$ protein was located on, or in the region of, lateral cell membranes of the uterine epithelium surrounding the forming implantation chamber (Figs. 8a and 8b). At higher magnification, the label appeared as distinct spots, distributed uniformly over the lateral membrane or in intracellular stores adjacent to it (Fig. 9). At this time, label was found only at the epithelial cells in the vicinity of the blastocyst and not in the blastocyst-free segments. All controls performed in immunocytochemistry showed only low nonspecific background staining in all phases investigated.

$7 d$ p.c. At 7 d p.c. when trophoblastic invasion starts at the abembryonic/antimesometrial pole, epithelium lining the implantation chamber was equipped with an extraordinarily large number of gap junctions as revealed by freeze-fracture replicas. On the basis of size and association with tight junctions, two types of gap junctions could be distinguished on the lateral membrane: small to medium size junctions are found intercalated within the highly proliferated tight junctional strands, showing regularly arranged rows of gap junctional particles (Fig. 4). Very large gap junctions (up to about $1 \mu \mathrm{m}^{2}$ in size) were distributed randomly in the lower portion of the lateral membrane (Fig. 6). At this phase, most of the large gap junctions were accompanied by loosely aggregated particles in the surrounding area. Corresponding pits were already seen on the Eface of the neighboring cell (Fig. 5). Morphometric measurement of the gap junctions on the lateral membranes yields a mean $\pm \mathrm{SE}$ value of $0.27 \pm 0.14 \mu \mathrm{m}^{2}$ which is $2.2 \pm 0.54 \%$ of the total membrane area examined $\left(265 \mu \mathrm{m}^{2}\right)$. Variation is considerable: some of the lateral membranes remained without any junctions while others had more than $20 \%$ of their surface area covered by gap junctions.

Lucifer yellow injected into the uterine epithelial cells in the implantation chamber was rapidly transferred to (up to 10th order) neighboring cells (Fig. 12). This highly increased cell-to-cell communication was found exclusively in the implantation chamber and not in the adjacent parts of the endometrium, i.e., the blastocyst-free segments (Table 2). These results are in agreement with those from freeze-fracture morphology demonstrating nearly no gap junctions between the cells of the blastocyst-free segments. Some cells are different, however, in exhibiting gap junctions which are as large and as numerous as those of the implantation chamber; there is no detectable correlation to the distance from the blastocyst.

Indirect immunofluorescence yielded an intense punctate immunoreaction in the epithelium of the implantation chamber (mesometrial as well as antimesometrial part), thus confirming the observations from freeze-fracture and dye injection. Interestingly, the same immunocytochemical pattern of the $26 \mathrm{~K}$ protein was also found in the blastocyst-free segments, in contrast to the $6 \mathrm{~d}$ p.c. stage (Table 2 ). 


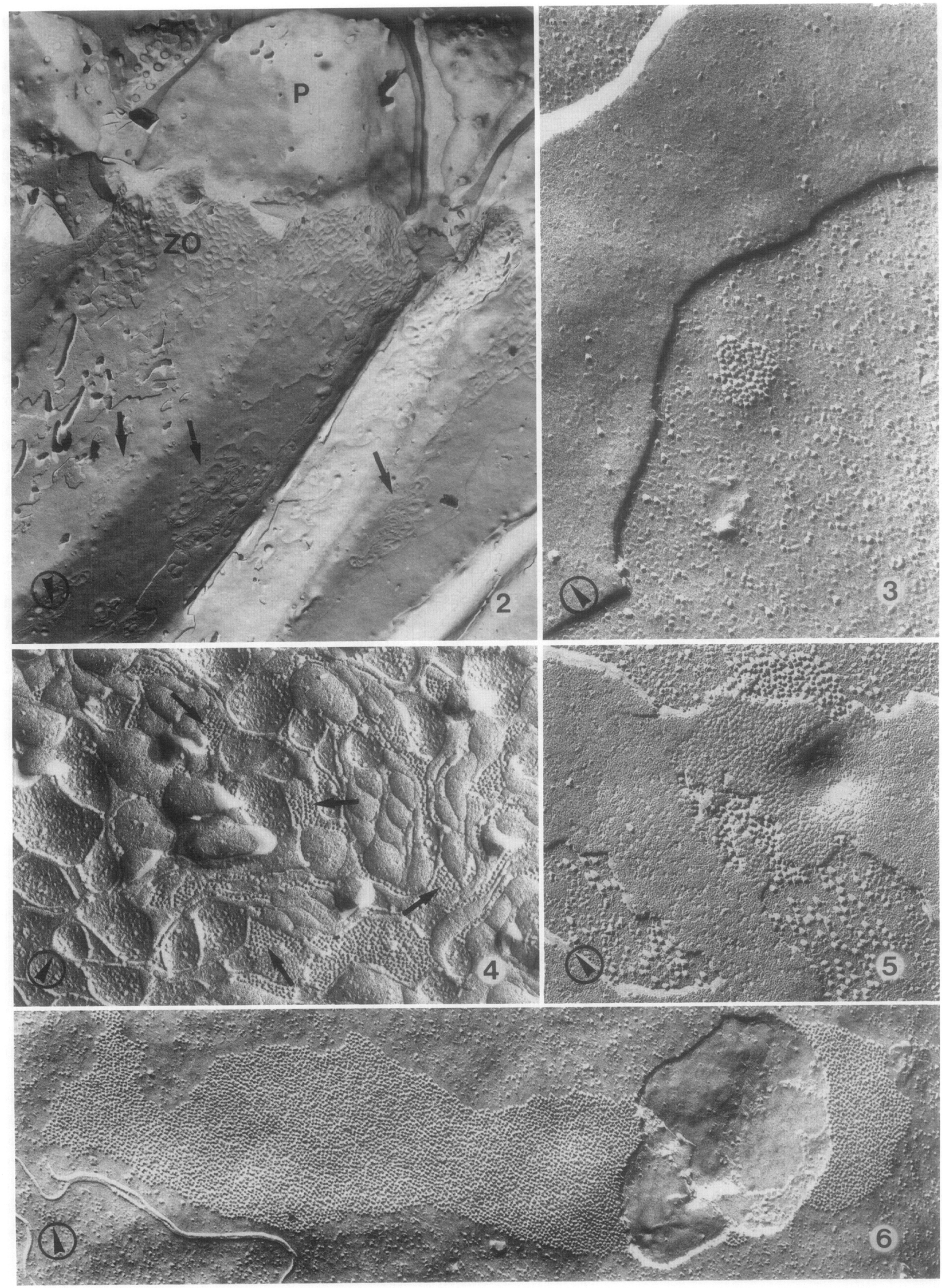


$8 d$ p.c. At 8 d p.c. most of the epithelial cells of the antimesometrial part of the implantation chamber have fused and formed large symplasms, while the fusion process has just begun at the placental folds (mesometrial region) which exhibit only small symplasms. The region of the lateral membranes of these cells and symplasms was decorated with immunofluorescent spots indicating the presence of the $26 \mathrm{~K}$ protein (Fig. 10). In the blastocyst-free segments, on the other hand, a high degree of cell-to-cell communication was observed (Table 1) 1 day after the presence of gap junction proteins had been demonstrated by the immunoreaction. However, morphological investigation of gap junctions by freeze-fracture was very difficult here, due to the highly interdigitating lateral membranes (Winterhager, 1985). Membrane fracture planes are extremely rarely found in freeze-fracture replicas, so that statistical evaluation of gap junction distribution and frequency is highly impracticable at this stage.

All data obtained with the different methods to detect gap junctions (freeze-fracture, immunocytochemistry, and microiontophoresis) offer evidence for a precise time course in establishing cell-to-cell communication starting with the appearance of the $26 \mathrm{~K}$ protein followed by aggregation of gap junction particles and, simultaneously, by dye coupling. All these phenomena start locally in the epithelium in the vicinity of the blastocyst and then spread out to the blastocyst-free segments 1 day later (Table 2).

\section{Pseudopregnancy}

Uterine epithelial cells investigated in comparable phases $(6,7$, and $8 \mathrm{~d}$ p. hCG) of pseudopregnancy demonstrated only few and small gap junctions comparable to the nonpregnant state. Accordingly, there was no appreciable labeling in indirect immunocytochemistry (Figs. 7a and 7b). Intracellular injection of Lucifer yellow performed at $7 \mathrm{~d} \mathrm{p}$. hCG (Table 1 and 2) gives evidence for a noncoupled state of the epithelium.

\section{Tubal Ligation Experiments}

Tubal ligation experiments permitted comparison of the blastocyst-bearing uterus with the blastocyst-free uterus within the same animal ( $7 \mathrm{~d}$ p.c.), and gave evidence that the appearance of gap junctions depended on the presence of a blastocyst. In freeze-fracture replicas, gap junctions were found exclusively in the epithelium of the implantation chamber at $7 \mathrm{~d}$ p.c. and not in the contralateral blastocyst-free uterus.

\section{DISCUSSION}

Rabbit uterine epithelial cells become junctionally coupled at the time of implantation as evidenced by freeze-fracture, immunocytochemistry, and intracellular injection of Lucifer yellow. Cell-to-cell communication via gap junctions is initiated locally in the vicinity of the blastocysts, i.e., precisely in the implantation chamber. This induction of gap junctions is clearly dependent on the presence of a blastocyst. The epithelium remains uncoupled in pseudopregnancy as well as in unilaterally pregnant animals in the blastocyst-free uterus (tubal ligation experiment). Using the different techniques we were able to trace a particular time course in gap junction formation in this tissue. First, the gap junction protein becomes detectable immunocytochemically at $6 \mathrm{~d}$ p.c., suggesting an increased expression of $26 \mathrm{~K}$ gap junction protein at that time. The appearance of the $26 \mathrm{~K}$ protein on, or in the region of, the lateral membranes precedes the formation of morphologically distinct plaques and of intact channels permitting dye transfer, observed 1 day later. Light microscopical immunocytochemistry hardly allows one to discriminate whether the $26 \mathrm{~K}$ protein is inserted in the lateral membrane or located in intracellular stores adjacent to the lateral membrane. It has been proposed that gap junction formation may indeed take place in two steps in other systems although the same set of techniques has not been used. This would explain why the junctions have been shown to assemble rapidly in the absence of ATP or protein synthesis (Epstein et al.,

FIGs. 2-6. Freeze-fracture micrographs. The encircled arrow indicates the direction of shadowing.

FIG. 2. Overview of the lateral membrane of uterine epithelial cells lining the forming implantation chamber $6 \mathrm{~d}$ p.c. The cells are characterized by dome-like protrusions $(\mathrm{P})$ and a highly proliferated zonula occludens $(\mathrm{ZO})$ with macular tight junctions on the lower portions of the membranes (arrows). $\times 9500$.

FIG. 3. Epithelial cell of a nonpregnant rabbit. Gap junctions are rarely found and consist of only a small aggregate of particles. $\times 95,000$.

FIG. 4. Implantation chamber ( $7 \mathrm{~d}$ p.c.). Numerous but smaller gap junctions are encircled by highly proliferated tight junctional strands. The particles are partly arranged in rows (arrows). $\times 80,750$.

FIG. 5. Growing gap junction, implantation chamber $(7 \mathrm{~d}$ p.c.). The gap junction plaque is surrounded by scattered particles which are not integrated yet. Remarkably, the corresponding pits are already found on the external leaflet of the neighboring cell, suggesting that even these aggregating particles represent probably complete channels. $\times 104,500$.

FIG. 6. Implantation chamber ( 7 d p.c.). A large gap junction with densely packed particles on the lower portion of the lateral membrane of an epithelial cell. $\times 71,250$. 

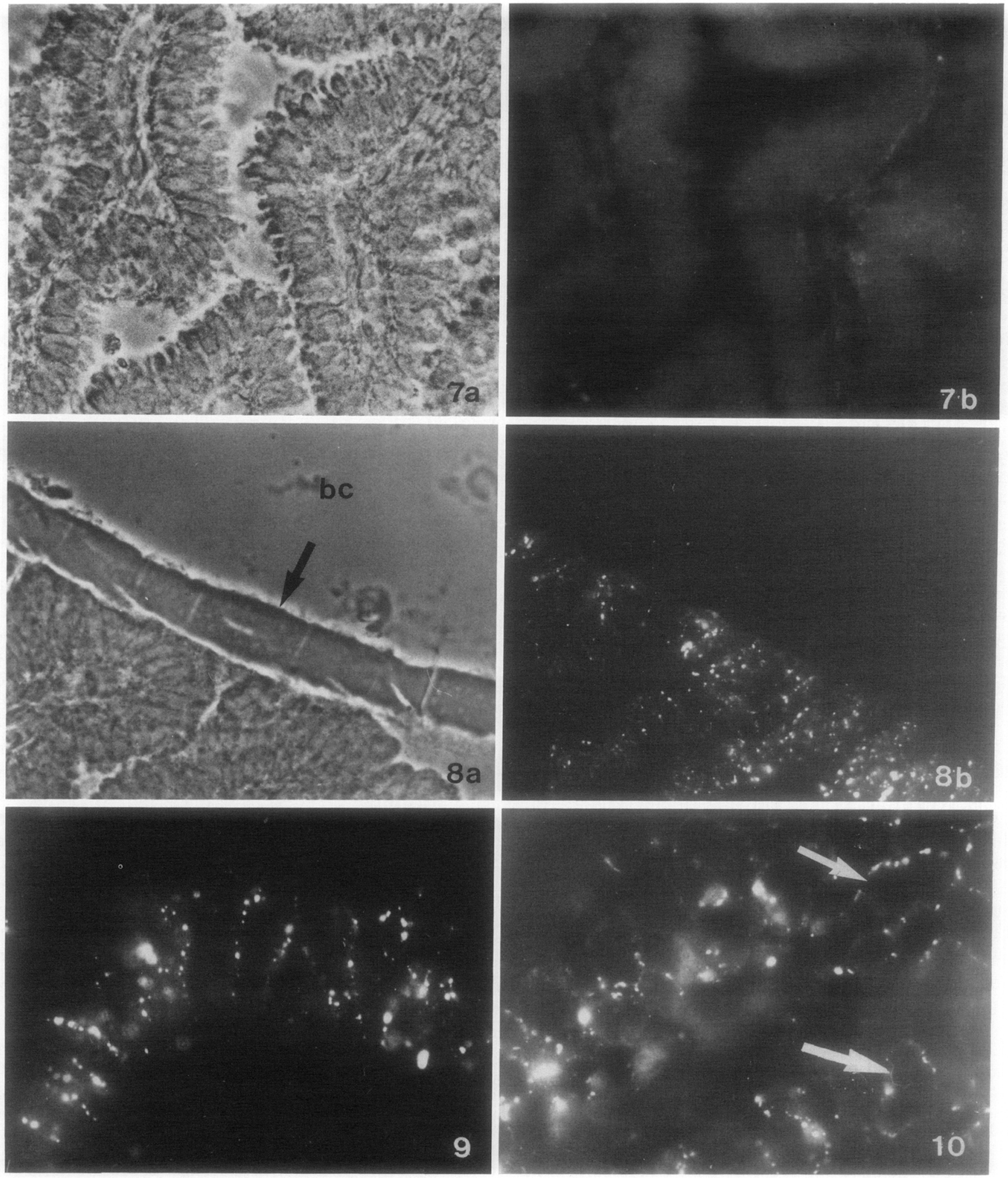

FrGs. 7-10. Immunocytochemical localization of $26 \mathrm{~K}$ protein (indirect immunofuorescence).

F1G. 7. The highly proliferated uterine epithelium in pseudopregnancy ( $7 \mathrm{~d} \mathrm{p}$. hCG) does not exhibit specific immunoreaction. (a) Phase-contrast, (b) immunofluorescence. $\times 304$.

FIG. 8. Forming implantation chamber ( $6 \mathrm{~d}$ p.c.). (a) Phase-contrast. The blastocyst is still surrounded by the coverings (arrow). (b) Fluorescent spots revealing a clear reaction to the $26 \mathrm{~K}$ protein on, or in the region of, the lateral membranes of the epithelium lining the implantation chamber. be, blastocyst cavity. $\times 304$.

FIG. 9. Higher magnification of uterine epithelial cells in the implantation chamber $(7 \mathrm{~d} \mathrm{p.c}$ ) shows that the antibody is bound in small spots located exclusively on, or adjacent to, the lateral cell membranes. $\times 475$.

FIG. $10.8 \mathrm{~d}$ p.c. An intensive immunoreaction is observed in the epithelium of the mesometrial folds including small symplasms (arrows). $\times 304$. 

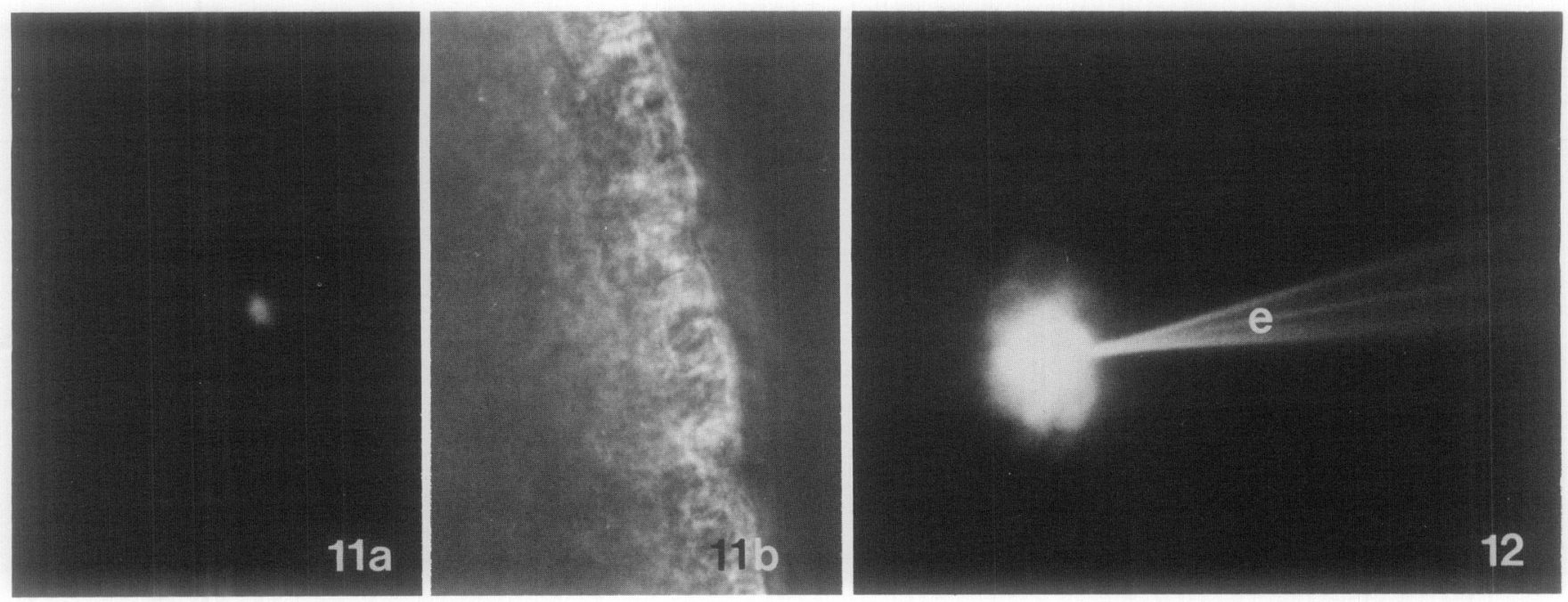

FIGS. 11-12. Dye-coupling with Lucifer yellow.

FIG. 11. (a) In a nonpregnant animal, dye remains in the injected epithelial cell. (b) Phase-contrast of the same specimen. $\times 304$.

Fli. 12. Highly coupled epithelial cells in the implantation chamber ( $f$ d p.c.). Note that the dye spreads from cell to cell with decrement. e, electrode. $\times 304$.

1977; Tadvalkar and Pinto da Silva, 1983). The rabbit uterine epithelium may offer particular advantages for detecting such a sequence of events. In contrast to other experimental systems, large scale gap junction formation takes place in a highly ordered and synchronized process that is clearly defined with respect to time and location.

Gap junction induction in the implantation chamber is one of the earliest known signs for blastocyst-derived signals which may be involved in preparing the endometrium for implantation. The existence of such locally acting signals has often been postulated but has only rarely been shown (for review see Heap et al., 1979, 1981; Gadsby et al., 1980; Kennedy, 1983). Systemic hormonal changes induced by the implanting embryo (e.g., via chorionic gonadotropin) are far better known (for review see Beier and Mootz, 1979). The postulated locally acting signals provided and/or activated by the blastocyst may be steroid hormones and/or mediators like histamine and prostaglandins (see for review Kennedy 1983) but any new classes of compounds cannot be excluded. It is well established that many compounds can regulate or induce gap junction formation in excitable as well as in nonexcitable cells. In the case of the myometrium, gap junction formation is induced during parturition in several species such as rat, rabbit, guinea pig, sheep, and human (Dahl and Berger, 1978; Garfield et al., 1979, 1980a,b; Dermietzel et al., 1984). This phe-

TABLE 1

Dye-Coupling Experiments in Different Reproductive Phases of Uterine Epithelium

\begin{tabular}{|c|c|c|c|c|c|}
\hline \multirow[b]{2}{*}{ Phase } & \multirow{2}{*}{$\begin{array}{c}\text { Number of } \\
\text { animals } \\
\text { investigated }\end{array}$} & \multicolumn{4}{|c|}{ Number of intracellular injections } \\
\hline & & Total & Noncoupled & $n_{1}$-coupled ${ }^{a}$ & $>n_{1}-$ coupled $^{a}$ \\
\hline Nonpregnancy & 3 & 41 & 39 & 2 & - \\
\hline \multicolumn{6}{|l|}{ Pregnancy } \\
\hline $6 \mathrm{~d}$ p.c. & $\mathbf{3}$ & & & & \\
\hline Blastocyst-free segments & & 9 & 7 & 2 & - \\
\hline Implantation chamber & & 28 & 19 & $\overline{9}$ & - \\
\hline $7 \mathrm{~d}$ p.c. & 3 & & & & \\
\hline Blastocyst-free segments & & 18 & 11 & 7 & - \\
\hline Implantation chamber & & 42 & - & 42 & 42 \\
\hline 8 d p.e. & 2 & & & & \\
\hline Blastocyst-free segments & & 60 & 13 & 47 & 44 \\
\hline \multicolumn{6}{|l|}{ Pseudopregnancy } \\
\hline $7 \mathrm{~d}$ p. hCG & 3 & 31 & 28 & 3 & - \\
\hline
\end{tabular}

${ }^{a} n_{1}$, direct neighboring cells (first order $n$ ). 
TABLE 2

SYNOPSIS OF RESULTS

\begin{tabular}{lccc}
\hline \multicolumn{1}{c}{ Phase } & Immunocytochemistry & Freeze-fracture & Dye-coupling \\
\hline Nonpregnancy & - & $-/(+)$ & - \\
Pregnancy & & & \\
6 d p.c. & - & $-/(+)$ & $(+)$ \\
Blastocyst-free segments & ++ & $-/(+)$ & $(+)$ \\
Implantation chamber & ++ & + & + \\
7 d p.c. & +++ & +++ & +++ \\
Blastocyst-free segments & & & +++ \\
Implantation chamber & +++ & Symplasms & Symplasms \\
8 d p.c. & Symplasms & $-/(+)$ & \\
Blastocyst-free segments & - & $-/(+)$ & - \\
Implantation chamber & - & $-/(+)$ & \\
Pseudopregnancy & - & & \\
7 d p. hCG. CG & & & \\
8 d p. hCG &
\end{tabular}

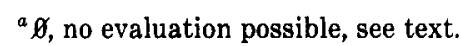

nomenon is probably related to a decrease in progesterone and an increase in estrogen and/or a higher level of prostaglandins (Garfield et al., 1980a,b). Gap junction formation in the canine trachea seems to be controlled by prostaglandin $\mathrm{E}_{2}$ or prostacyclin $\left(\mathrm{PGI}_{2}\right.$ ) (Agrawal and Daniel, 1986).

Synthesis of prostaglandins is accompanied by an increase in intracellular cAMP which is believed to induce an increase in gap junctional area (Lawrence et al., 1978; Flagg-Newton and Loewenstein, 1981; De Mazière and Scheuermann, 1985; in't Veld, 1985). All these factors may, therefore, be involved in eliciting the cell-to-cell communication via gap junctions in the rabbit uterine epithelium. Their respective roles should be accessible to experimental investigation in this system due to the exact time course of events reported here.

Gap junctions are frequently thought to be involved in regulating proliferation, differentiation, and coordination of activities of the component cells. In nearly all tissues some degree of cell coupling is found so that it seems surprising that uterine epithelium cells lack such cooperation in the nonpregnant, pseudopregnant, and early pregnant stage up to the time of implantation. At implantation it seems to be necessary for this epithelium to convert to another physiological state characterized by a high degree of metabolic coupling. It may be that the program of gap junction synthesis can only be triggered at a specific stage when the uterine epithelial cells stop to proliferate and enter terminal differentiation. A coordinated and synchronized response of the uterine epithelium may be required for the initiation of the complex set of changes constituting part of the so-called implantation reaction (Finn, 1977). The formation of gap junctions in the epithelium may well serve this function.

In conclusion, blastocyst-induced gap junction formation in rabbit uterine epithelium may be of considerable interest both as a significant element of implantation physiology and as a cell biological model system.

This work was supported by DFG Grants Wi 774/1-1 (to E.W.), Hu 204/9-4 (to D.F.H.), De 292/2-1 (to R.D.), and De 181/9-6 (to H.-W.D.). We thank Gaby Bock, Gerda Helm, Petra Kalweit, Gisela Mathieu, and Diana Seelis for excellent technical help.

\section{REFERENCES}

Agrawal, R., and Daniel, E. E. (1986). Control of gap junetion formation in canine trachea by arachidonic acid metabolites. Amer. $J$. Physiol. 250(3), C495-C505.

BEIER, H. M., and MoOTZ, U. (1979). Significance of maternal uterine proteins in the establishment of pregnancy. Ciba Found. Symp. 64, 111-140.

DAHL, G., and BERGER, W. (1978). Nexus formation in the myometrium during parturition and induced by estrogen. Cell Biol. Int. Rep. 2, 381-387.

De Mazière, A. M. G. L., and ScheuermanN, D. W. (1985). Increased gap junctional area in the rat liver after administration of dibutyryl cAMP. Cell Tissue Res. 239, 651-655.

DENKER, H.-W. (1986). Epithel-Epithel-Interaktionen bei der Embryo-Implantation: Ansätze zur Lösung eines zellbiologischen Paradoxons. Verh. Anat. Ges. 80; Anat. Anz. 158 (Suppl.), 93-114.

Dermietzel, R., LeIBSTein, A., FriXen, U., JANSSEN-'IIMMEN, U., Traub, O., and WILlecke, K. (1984). Gap junctions in several tissues share antigenic determinants with liver gap junctions. $E M B O$ J. 3, 2261-2270.

EpSTein, M. L., Sheridan, J. D., and Johnson, R. G. (1977). Formation of low-resistance junctions in vivo in the absence of protein synthesis and ATP production. Exp. Cell Res. 104, 25-30.

FINN, C. A. (1977). The implantation reaction. In "Biology of the uterus" (R. M. Wynn, Ed.), pp. 245-308. Plenum, New York. 
FlagG-Newton, J. L., and Loewenstein, W. R. (1981). Cell junction and cyclic AMP. II. Modulation of junctional membrane permeability, dependent on serum and cell density. J. Membr. Biol. 63, 123-131.

Gadsby, J. E., Heap, R. B., and Burton, R. D. (1980). Oestrogen production by blastocyst and early embryonic tissue of various species. J. Reprod. Fertil. 60, 409-417.

GaRfield, R. E., KANNAN, M. S., and Daniel, E. E. (1980b). Gap junction formation in myometrium: Control by oestrogens, progesterone, and prostaglandins. Amer. J. Physiol 238, C81-C89.

Garfield, R. E., MerReTT, D., and Grover, A. K. (1980a). Gap junction formation and regulation in myometrium. Amer. J. Physiol. 239, C217-C228.

Garfield, R. E., Rabideau, S., Challis, J. R. G., and Daniel, E. E. (1979). Hormonal control of gap junction formation in sheep myometrium during parturition. Biol. Reprod. 21, 999-1007.

GotTsChewski, G. H. M., and ZimmermaNN, W. (1970). "Embryologische Untersuchungsmethoden für Laboratoriumssäugetiere." Schaper, Hannover.

Heap, R. B., Flint, A. P. F., and Gadsby, J. E. (1981). Embryonic signals and maternal recognition. In "Cellular and molecular aspects of implantation" (Glasser and Bullock, Eds.), pp. 311. Plenum, New York.

Heap, R. B., Flint, A. P. F., Gadsby, J. E., and RICE, C. (1979). Hormones, the early embryo and the uterine environment. $J$. Reprod. Fertil. 55, 267-275.

IN'T VELD, P. (1985). Gap junctions between pancreatic B-cells are modulated by cyclic AMP. Eur. J. Cell Biol. 36, 269-276.

IWATsuki, N., and Petersen, O. H. (1979). Direct visualization of cell to cell coupling: Transfer to fluorescent probes in living mammalian pancreatic acini. Pfiügers Arch. 380, 277-281.

Janssen-Ttmmen, U., Traub, O., Dermietzet, R., RaBes, H. M., and WILLECKE, K. (1986). Reduced number of gap junctions in rat hepatocarcinomas detected by monoclonal antibody. Carciogenesis 7 , 1475-1482.

KENNEDY, T. G. (1983). Embryonic signals and the initiation of blastocyst implantation. Aust. J. Biol. Sci. 36, 531-543.

LawRENCE, T. S., BeERS, W. H., and GILUDA, N. B. (1978). Transmission of hormonal stimulation by cell-to-cell communication. Nature (London) 272, 501-506

Psychoyos, A. (1976). Hormonal control of uterine receptivity for nidation. J. Reprod. Fertil. Suppl. 25, 17-28.

SteWART, W. W. (1978). Functional connections between cells as revealed by dye-coupling with a highly fluorescent naphthylamide tracer. Cell 14, 741-759.

Tadvalkar, G., and PinTo da Silva, P. (1983). In vitro rapid assembly of gap junctions is induced by cytoskeleton disruptors. $J$. Cell Biol. 96, 1279-1287.

WINTERHAGER, E. (1985). Dynamik der Zellmembran: Modellstudien während der Implantationsreaktion beim Kaninchen. Habilitationsschrift, Medizinische Fakultät, RWTH Aachen, West-Germany.

Winterhager, E., Busch, L. C., and KUhnel, W. (1984). Membrane events involved in fusion of uterine epithelial cells in pseudopregnant rabbits. Cell Tissue Res. 235, 357-363.

WINTERHAGER, E., and KUHNEL, W. (1982). Alterations in intercellular junctions of the uterine epithelium during the preimplantation phase in the rabbit. Cell Tissue Res. 224, 517-526. 